\title{
Supranumerary Barrels Develop in the Somatosensory Cortex of Mice, After the Implantation of the Vibrissal Follicle Parts Containing Large Numbers of Receptors
}

\author{
F.L. Andrés \\ Rua Tristao Vaz No. 37 \\ $1^{\circ}$ Esq., 1400 Lisboa, Portugal
}

\section{SUMMARY}

In the mouse whiskerpad there is a group of vibrissal follicles arranged in five rows, which are topologically represented in the contralateral somatosensory cortex by the barrelfield.

Each vibrissal follicle is a specialized sensory organ containing a large number of receptors, mostly Merkel cells.

In these experiments, the parts of the vibrissal follicles containing most of the receptors were transplanted to different regions of the whiskerpad of newborn mice, to know whether "new", supranumerary barrels could develop.

The results confirm this hypothesis. However, the "new" barrels are not topologically represented in the barrelfield, as normal barrels do.

\section{INTRODUCTION}

The barrelfield is a cortical map in which the vibrissal follicles of the contralateral whiskerpad of the mouse are topologically represented. A given barrel, in a barrelfield, has a size that is similar to that of its equivalent in the contralateral barrelfield.

Reprint address

F.L. Andrés

Rua Tristao Vaz No. 37

$1^{\circ}$ Esq., 1400 Lisboa, Portugal
It has been demonstrated that modifications of the periphery (whiskerpad) in mice, produced early after birth (until postnatal days 5 or 6), induce modifications in the corresponding somatosensory cortex $/ 1,3,6 /$. These findings strengthened the hypothesis that even in normal development, the pattern of sensory organs in the periphery, the vibrissal follicles, plays an important role in the establishment of a cortical map /9, 10/ (Fig. 1a and b).

The vibrissal follicles are highly specialized sensory organs, containing different types of receptors, mostly Merkel cells $/ 2 /$. These cells are concentrated in the upper part of the vibrissal follicle root, called "superior enlargement" (SE, Fig. 2a).

In these experiments, SEs of embryonic and adult mice vibrissal follicles were transplanted to different regions of the whiskerpad of newborn mice, to know whether they could induce the formation of "new", supranumerary barrels in the corresponding barrelfield.

\section{MATERIALS AND METHODS}

\section{Animals}

The mice used in these experiments were from a $\mathrm{C} 3 \mathrm{HeB} /$ Fej stock.

Twenty eight animals were operated, on the day of birth. Twenty four received transplants and four were used as non-host controls.

They were anesthetized by cooling, before the operations. During the operations they were kept fixed onto a small, also cooled platform.

After the operations, all mice were warmed up under a light bulb before being returned to their mothers. 


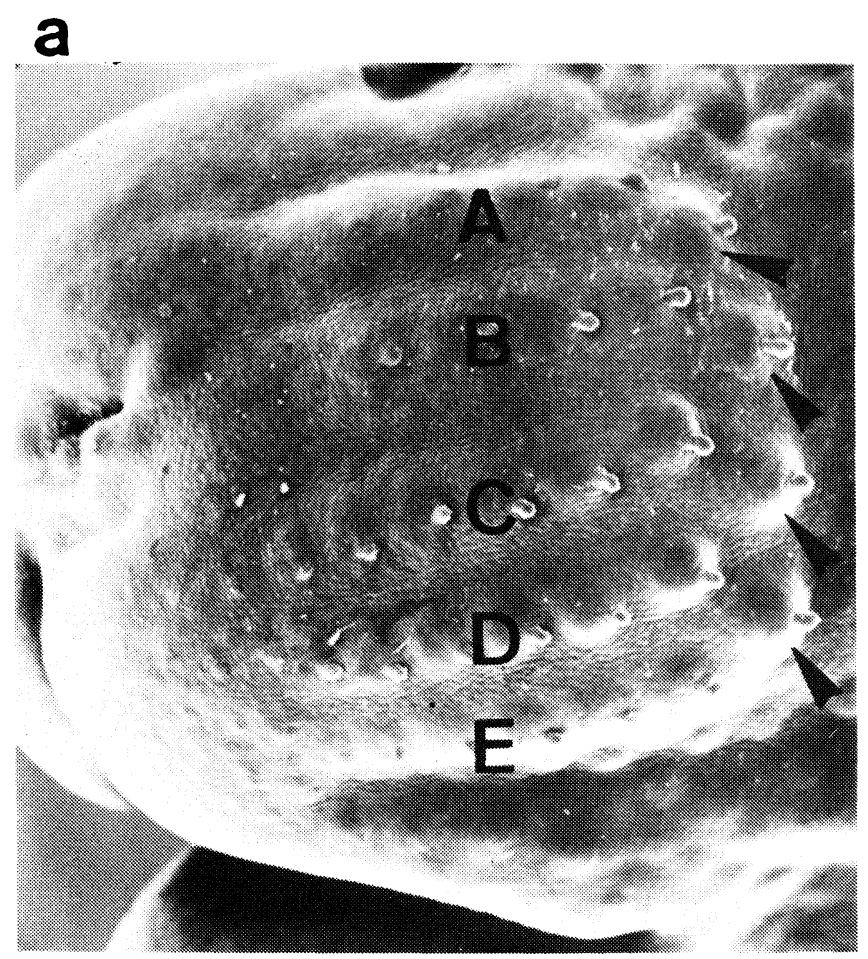

Fig. 1. a) Scanning electron micrograph of the left whiskerpad from a mouse embryo with 15 days of gestation. Letters indicate rows of vibrissal follicles. Arrowheads indicate the "straddlers" (from top to bottom: $\alpha, \beta, \gamma, \delta$. Dorsal is up; rostral to the left. $\times 180$.

\section{Preparation of the Transplants (SEs)}

The donors were sacrificed before the removal of the vibrissal follicles. Embryonic mice were anesthetized by deep cooling; the adults with an overdose of pentobarbitalum natricum (Nembutal, Abbott).

The technique of removal of the vibrissal follicles was the same for animals of both ages.

The whiskerpads were cleaned with $70 \%$ ethanol, removed with scissors and dipped into cooled Ringer solution. Several containers were prepared in advance to receive the vibrissal follicles in all the intermediary phases of dissection, until the SEs were finally obtained.

Individual vibrissal follicles were dissected from the whiskerpads using two pairs of fine forceps. From each follicle were discarded: the lower half, and the part close to the emergence of the hair (see Fig. 2a). What was left consisted of the SE surrounded by a fragment of the follicle capsule. The latter was finally peeled off with a fine forceps, and the SE, now ready b

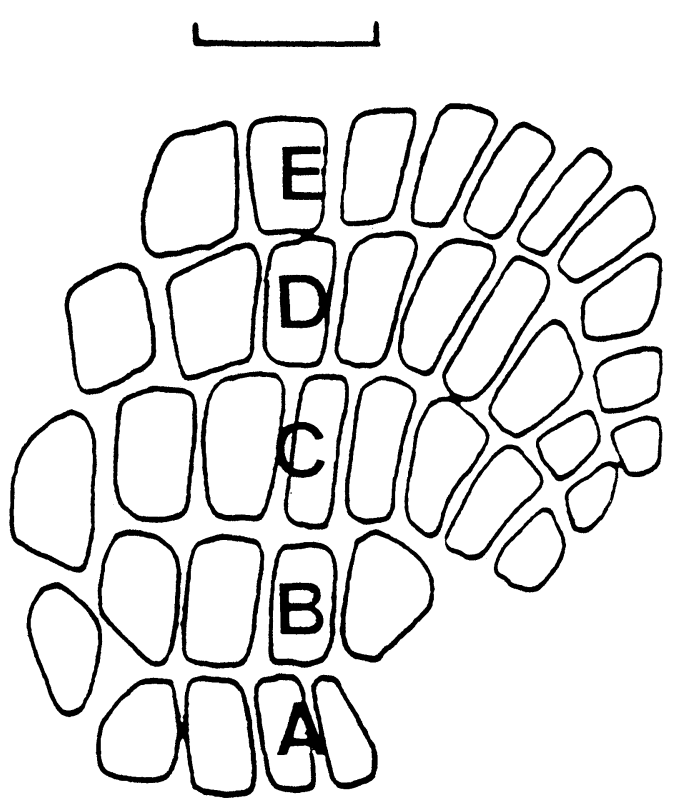

Fig. 1. b) Camera lucida drawing of the right barrelfield, corresponding to the left whiskerpad. Letters indicate rows of barrels corresponding to rows of vibrissal follicles. Dorsal is up; rostral to the right. Bar $=500 \mathrm{um}$.

for the transplantation, was deposited in clean cooled Ringer solution.

\section{Transplantation of SEs of Adult Vibrissae}

In 17 mice, from 1 to 8 SEs of adult vibrissae were transplanted to the middle portion of the space between rows $B$ and $C$ of the left whiskerpad (see Fig. 1a).

The skin incisions (with the length of about $1 \mathrm{~mm}$ ), were made superficial with the sharp tip of a number 11 blade (Swann-Morton), and the hemorrhages stopped with small fragments of Spongostan Special (M.E.D.U. D-25, Ferrosan). Afterwards, the SEs were introduced into the wound with a fine forceps. Finally, the skin around the wound was cleaned with Ringer solution. No suture was used because the small wound usually closed.

In two other mice, used as controls, the operations were also made, but no SE was deposited into the wound. 


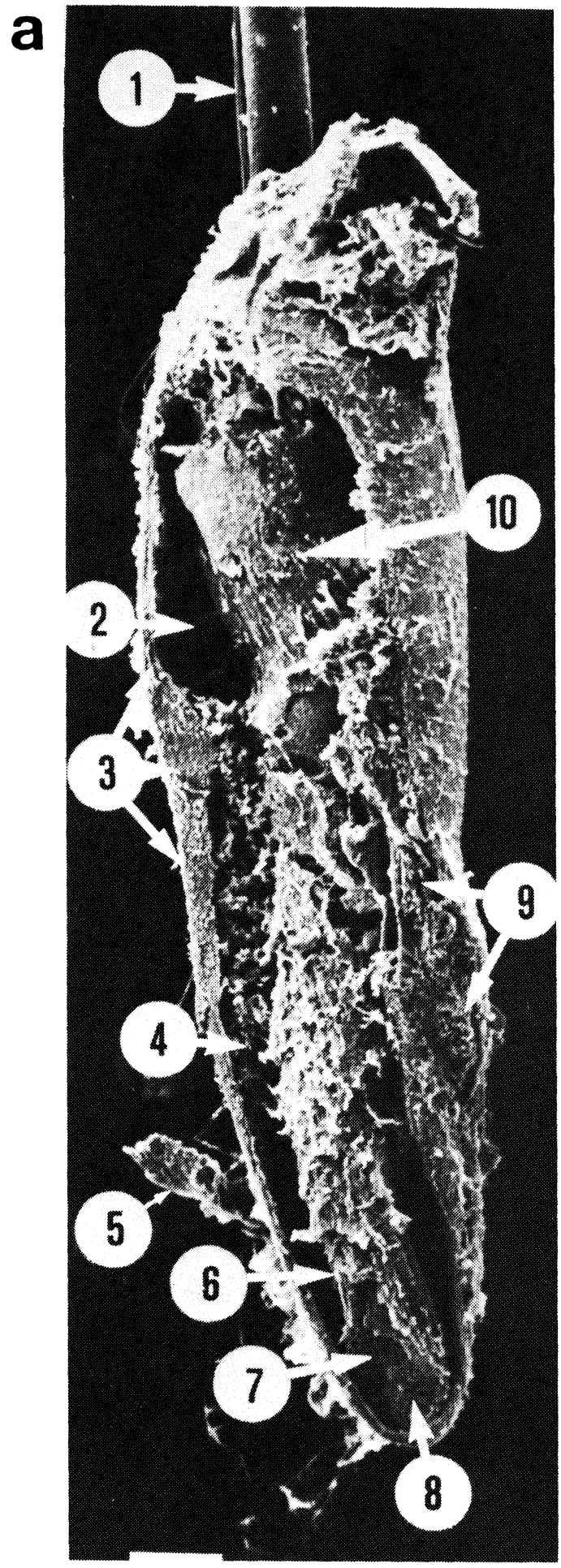

Fig. 2. a) Scanning electron micrograph of an adult vibrissal follicle. Part of its capsule has been removed to show inner structure. 1. hair shaft; 2. ring sinus; 3. capsule; 4. cavernous sinus; 5. striated muscle fiber; 6 . root; 7 and 8 . papilla of the hair; 9. two bundles of nerve fibers innervating the vibrissal follicle; 10. superior enlargement (SE). Bar $=100 \mathrm{um}$. 


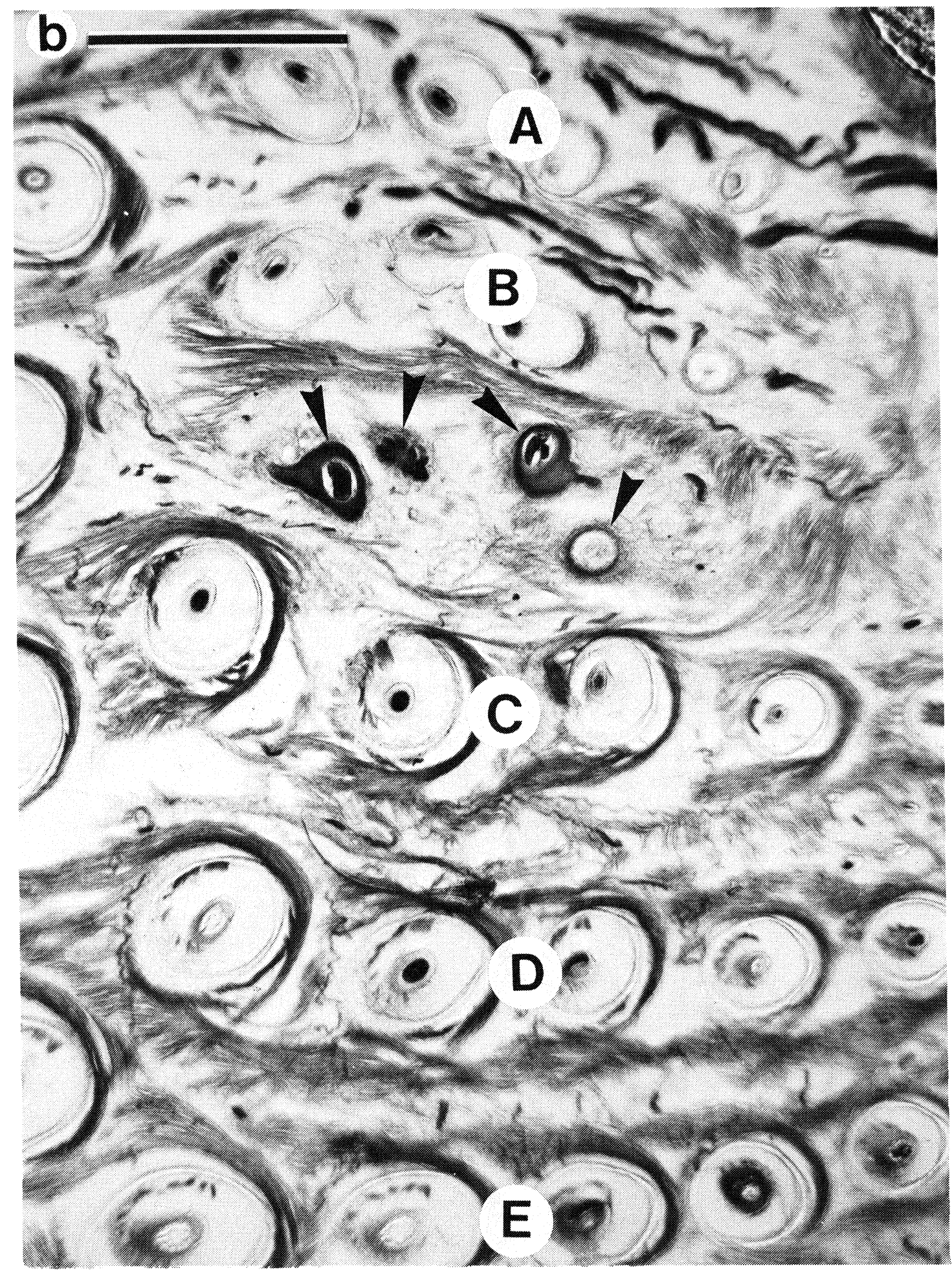

Fig. 2. b) Photomicrograph of cryostate section made tangential to the left whiskerpad of case $5 . \quad A, B, C, D$, and $E$, indicate rows of vibrissal follicles; arrowheads indicate the 4 SE transplants deposited in this case, between rows $B$ and $C$. Dorsal is up; rostral to right. $B a r=1 \mathrm{~mm}$.

\section{Transplantation of SEs of Embryonic Vibrissae}

In 7 animals, 5 or 6 embryonic SEs were first im- mersed in Nerve Growth Factor (NGF), and then transplanted to the dorsal region of the sapce between rows $\mathrm{C}$ and $\mathrm{D}$ (see Fig. 1a). 
The skin incisions were made as for the first group of operated mice, and also in the left whiskerpad.

In two other mice, used as controls, a drop of NGF was deposited into the wound, but no SE.

No post-operative antibiotic was used after the transplantation of SEs of either embryonic or adult vibrissae.

\section{Survival Times and Preparation of Tissues for Histology}

The survival times varied from 26 to 54 days (see Table 1).

Before perfusion, all animals were anesthetized with pentobarbitalum natricum (Nembutal, Abbott) i.p. $(60 \mathrm{mg} / \mathrm{Kg})$. Then, they were perfused through the heart with $10 \%$ neutralized formalin in $0.9 \% \mathrm{NaCl}$. They were decapitated immediately afterwards, and the heads were left in the fixative overnight. The brains, as well as the whiskerpads were removed and kept in the same solution for a few days. Afterwards, both of them were transferred to a $20 \%$ solution of sucrose in phosphate buffer, for a few hours. Then they were serially cut in a cryostat (at about $-16^{\circ} \mathrm{C}$ ), in $40 \mathrm{um}$ thick sections.

The brain sections were stained with cresyl violet, and the whiskerpad sections with a modified Liesegang technique $/ 4 /$.

\section{RESULTS}

\section{Mice Which Received Transplants of adult SEs}

In 8 of the 17 mice that had received adult SE transplants (in the sapce between rows $B$ and $C$, see Fig. $2 b$, corresponding to case 5 in which 4 transplants are visible at the level of this cryostat section), the barrelfields were altered.

In all these cases the transplants were well innervated by the host nerve fibers (see Fig. $3 a$ and $b$ ). However, the innervation was also good in 3 other cases which did not show any supranumerary barrel.

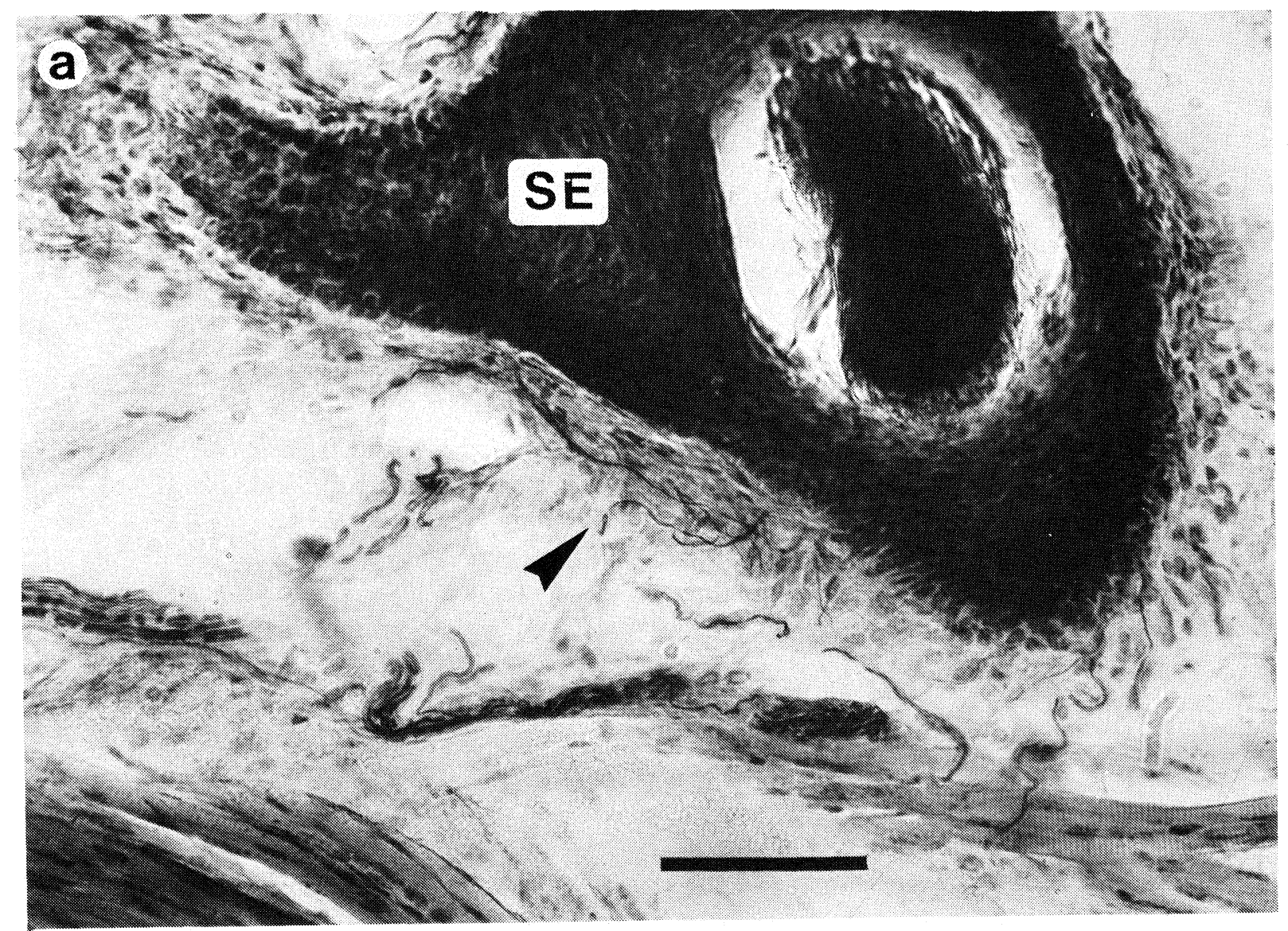

Fig. 3. a) Photomicrograph showing one "superior enlargement" (SE) transplanted to case 5 and part of the innervation that it received from the host. Arrowhead indicates nerve fibers, stained with a modified Liesegang stain. Survival time was 41 days. $\mathrm{Bar}=200 \mathrm{um}$. 


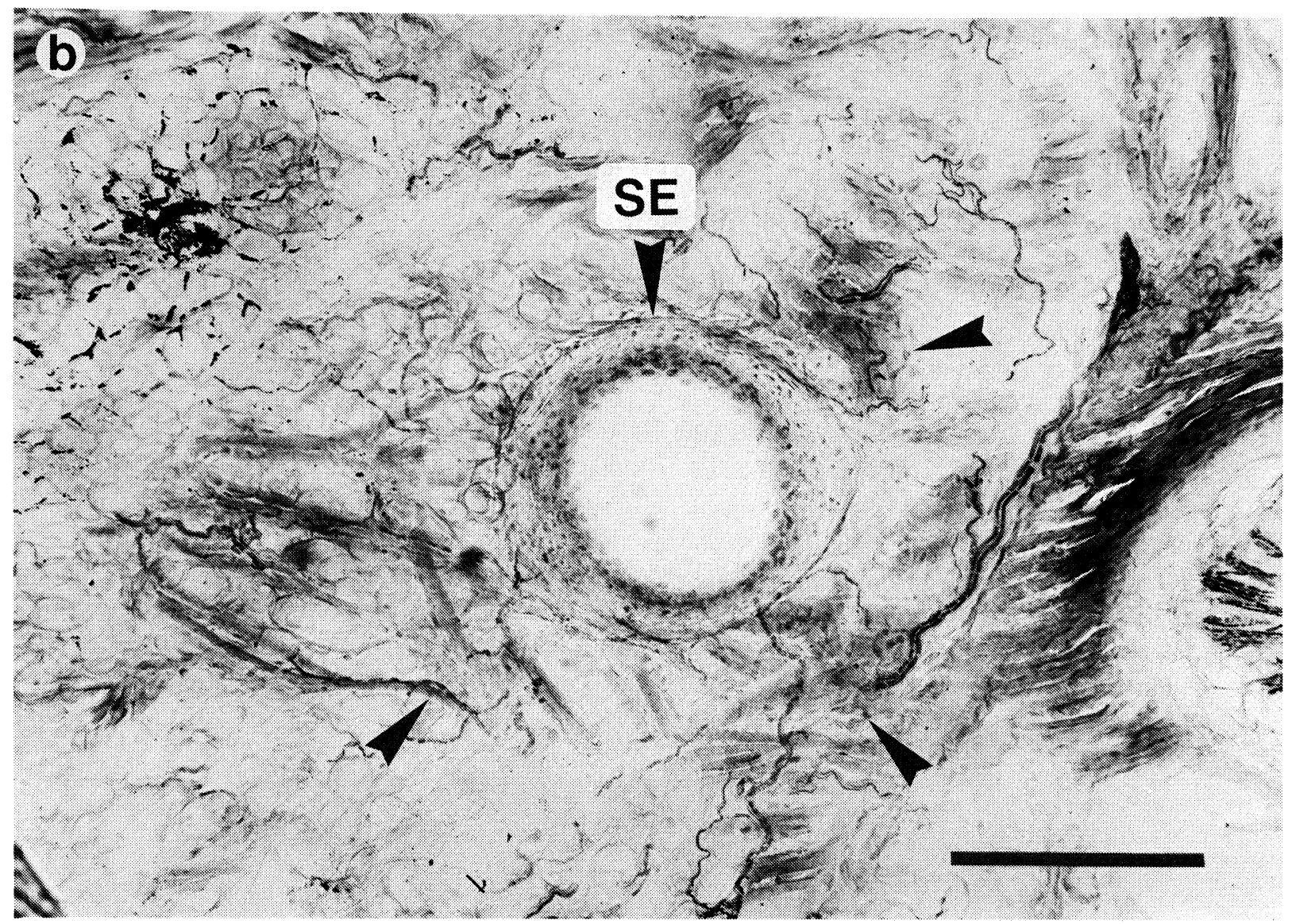

Fig. 3. b) Photomicrograph showing one SE transplanted to case 6 and part of the innervation that it received from the host. Arrowheads indicate nerve fibers, stained with a modified Liesegang stain. Bar $=100 \mathrm{um}$.

In case 1 , a barrel larger than normal was found in row $\mathrm{C}$ (see arrow in Fig. 4a, and Table 1). It corresponds, in the periphery, to one vibrissal follicle that was adjacent to the 3 transplants deposited in this case.

In case 2 (see Fig. $4 \mathrm{~b}$ and Table 1), in which one transplant had been deposited, one barrel was missing in row B (3 barrels were found instead of the normal number of 4). The remaining 3 row $B$ barrels are apparently larger than normal as well as barrel $\mathrm{C} 1$ (asterisc in Fig. 4b).

In case 3 (see Fig. 4c and Table 1), which received one transplant, only 2 barrels were found in row B. One of these barrels is apparently larger than normal (asterisc in Fig. 4c), as well as straddler beta and the adjoining barrel $\mathrm{C} 1$ (arrows in Fig. 4c).

In cases $4,5,6,7$, and 8 supranumerary barrels are visible in the rostral part of row B (see cases 4, and 5 as examples, in Figs. 4d, and e and Table 1).

\section{Mice Which Received Transplants of Embryonic SEs}

In 5 of the 7 mice that received 5 or 6 embryonic SEs (which had been previously dipped in NGF), in the dorsal region of the space between rows $\mathrm{C}$ and D, supranumerary barrels were found. Also in these cases the transplanted SEs were relatively well in nervated by the host nerve fibers.

In case 9 (Table 1), barrel $\mathrm{C} 1$ (asterisc in Fig. 5a), corresponding to the region where the transplants were deposited in the periphery, is smaller than normal, and a supranumerary barrel is visible in the rostral part of row B (see Fig. 5a).

In cases 10, 12, and 13, supranumerary barrels are visible in the rostral part of row B (see Figs. 5b, $\mathrm{d}$ and $\mathrm{e}$ ).

In case 11 (see Table 1 and Fig. 5d), an apparently supranumerary barrel is found in the rostral part of row $\mathrm{D}$. 

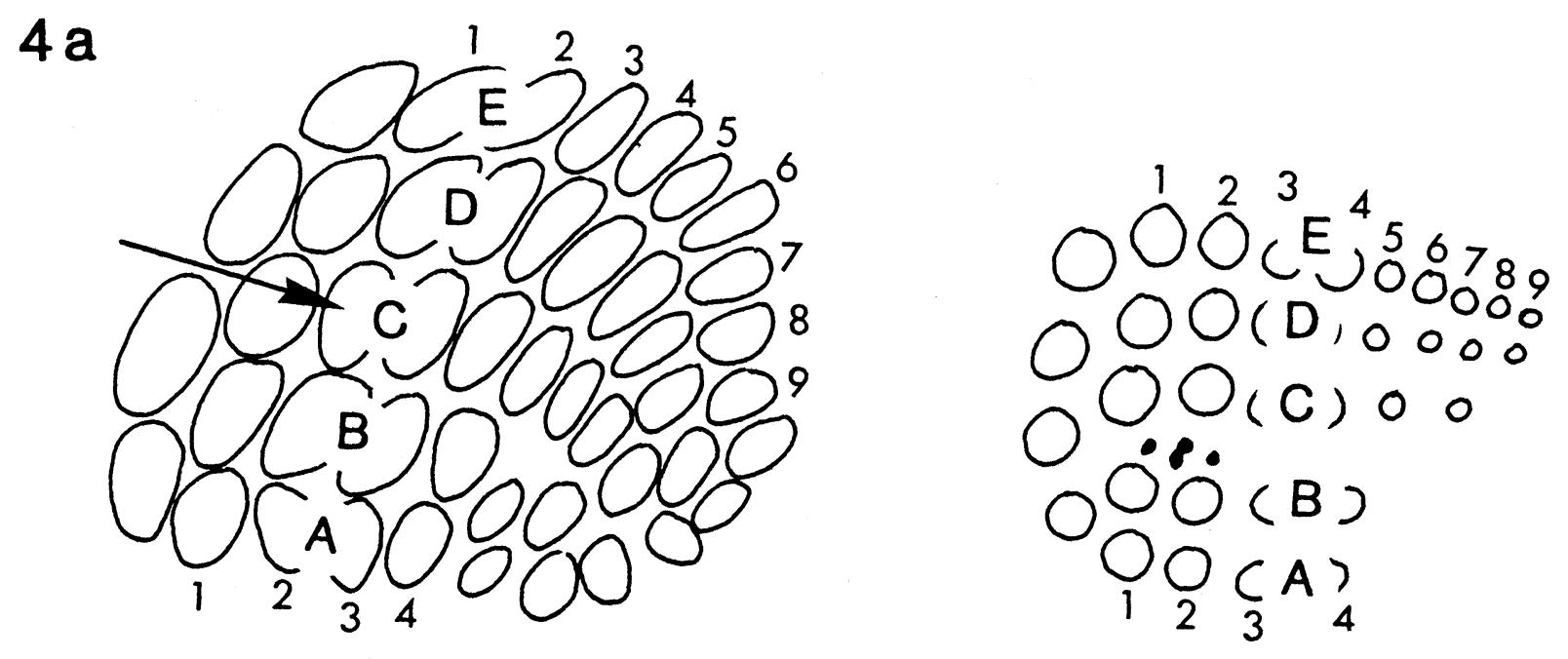

\section{Case 1}

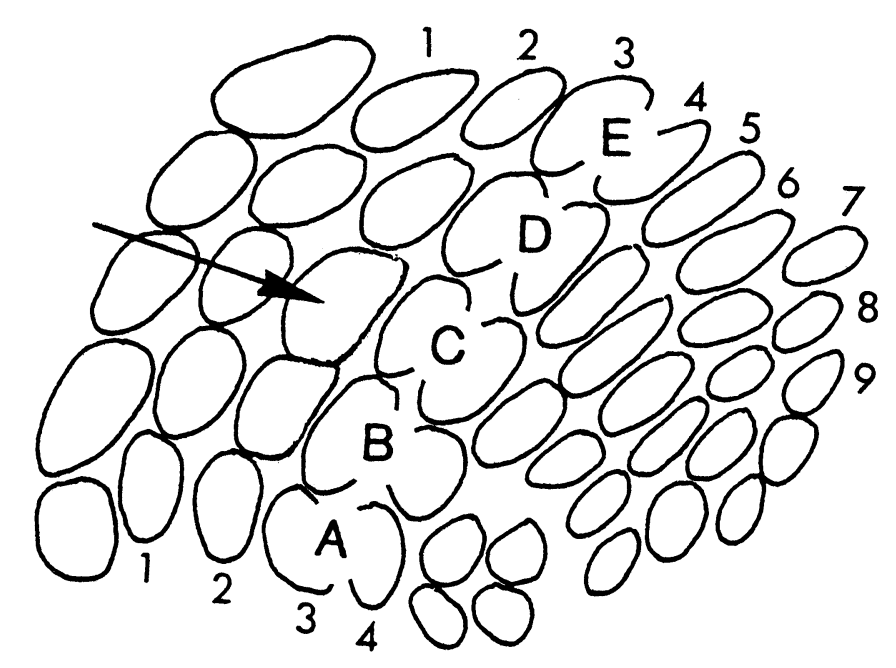

Fig. 4. Each part is divided in four quadrants. In the lower left quadrant is indicated the name of the case. In the upper left quadrant, is a camera lucida drawing from serial sections of the left barrelfield. (Its position has been inverted to facilitate the comparison with the right barrelfield, corresponding to the operated left whiskerpad). In the upper right quadrant is a drawing of the left whiskerpad which has been rotated by $180^{\circ}$ also to facilitate its comparison with right barrelfield (dorsal is to bottom; rostral is to the right). In the lower right quadrant is a camera lucida drawing of the right barrelfield whose orientation is correct (dorsal is up; rostral to the right). (This distribution is also valid for Fig. 5).

a) Case 1. Arrow indicates barrel $\mathrm{C} 2$ which is apparently larger than the corresponding barrel (see barrel indicated by an arrow in the upper left quadrant), in the opposite, intact, barrelfield. This barrel, C2, corresponds to vibrissal follicle C2, which is adjacent to the SE transplants deposited between rows B and C (see black dots in the drawing of the left whiskerpad, in the upper right quadrant). Lettering and numbering are used to indicate the position of vibrissae and corresponding barrels. It applies for Figs. 4 and 5. 


\begin{tabular}{|c|c|c|c|c|c|c|c|c|c|c|c|c|c|}
\hline 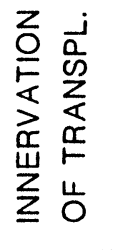 & + & $\begin{array}{l}+ \\
+ \\
+\end{array}$ & $\begin{array}{l}+ \\
+ \\
+\end{array}$ & + & $\begin{array}{l}+ \\
+ \\
+\end{array}$ & + & + & + & $\begin{array}{l}+ \\
+ \\
+\end{array}$ & $\begin{array}{l}+ \\
+ \\
+\end{array}$ & $\begin{array}{l}+ \\
+ \\
+\end{array}$ & + & + \\
\hline 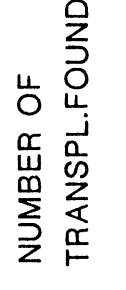 & M & - & - & 0 & $\nabla$ & $m$ & $\boldsymbol{C}$ & $\begin{array}{l}2 \\
\vdots \\
\infty \\
1 \\
N\end{array}$ & 10 & $\begin{array}{l}\text { อ } \\
0 \\
1 \\
f\end{array}$ & $r$ & $\mathbf{N}$ & 10 \\
\hline 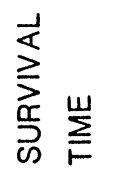 & $\begin{array}{l}0 \\
0 \\
\mathbf{N}\end{array}$ & $\begin{array}{l}0 \\
0 \\
\mathcal{N}\end{array}$ & $\begin{array}{l}\mathbf{D} \\
\mathcal{O} \\
\mathbf{N}\end{array}$ & $\begin{array}{l}8 \\
8 \\
0\end{array}$ & $\begin{array}{l}0 \\
\sigma \\
\end{array}$ & $\begin{array}{l}7 \\
7 \\
8\end{array}$ & $\begin{array}{c}0 \\
\sigma \\
8\end{array}$ & $\begin{array}{l}0 \\
\sigma \\
+\end{array}$ & $\begin{array}{l}\text { ठ } \\
\dot{~}\end{array}$ & $\begin{array}{l}0 \\
\dot{0}\end{array}$ & $\begin{array}{l}0 \\
\dot{m}\end{array}$ & $\begin{array}{l}0 \\
\dot{~}\end{array}$ & $\begin{array}{l}0 \\
+ \\
m\end{array}$ \\
\hline 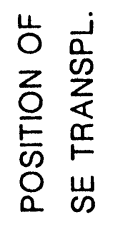 & $\underset{\mathbf{m}}{\stackrel{0}{\longrightarrow}}$ & $\vec{m}$ & $\underset{m}{\dot{m}}$ & $\vec{\omega}$ & $\underset{m}{\dot{m}}$ & $\vec{\omega}$ & $\overrightarrow{0}$ & $\underset{\mathbf{m}}{\vec{u}}$ & $\overrightarrow{0}$ & $\overrightarrow{\mathcal{U}}$ & $\overrightarrow{0}$ & $\overrightarrow{0}$ & $\overrightarrow{0}$ \\
\hline 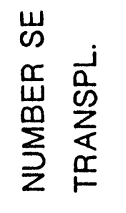 & $m$ & $r$ & $r$ & 10 & $\infty$ & $\infty$ & $\infty$ & $\infty$ & $\begin{array}{l}0 \\
1 \\
1 \\
1\end{array}$ & $\begin{array}{l}0 \\
1 \\
0\end{array}$ & $\begin{array}{l}0 \\
1 \\
6\end{array}$ & $\begin{array}{l}0 \\
1 \\
0\end{array}$ & $\begin{array}{l}0 \\
1 \\
6\end{array}$ \\
\hline 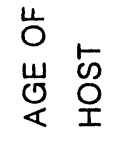 & ○ & ○ & 임 & ○ & 임 & $\begin{array}{l}\text { 음 } \\
\text { (n) }\end{array}$ & 웃 & 웅 & 용 & 웅 & $\begin{array}{l}0 \\
0\end{array}$ & 욤 & ○ \\
\hline 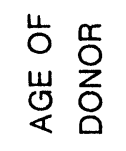 & 운 & $\frac{0}{4}$ & 우 & $\frac{0}{4}$ & $\frac{0}{4}$ & 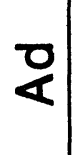 & 운 & 웅 & $\begin{array}{l}0 \\
0 \\
0\end{array}$ & $\begin{array}{l}0 \\
\stackrel{0}{\sigma}\end{array}$ & $\begin{array}{l}0 \\
\sigma \\
\sigma\end{array}$ & $\begin{array}{l}0 \\
\sigma\end{array}$ & $\frac{0}{\sigma}$ \\
\hline 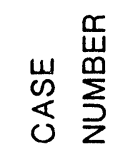 & $r$ & $\mathbf{N}$ & $m$ & 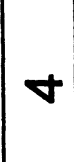 & م & $\boldsymbol{0}$ & $N$ & $\infty$ & の & 음 & 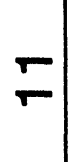 & $\underset{N}{ }$ & m \\
\hline
\end{tabular}

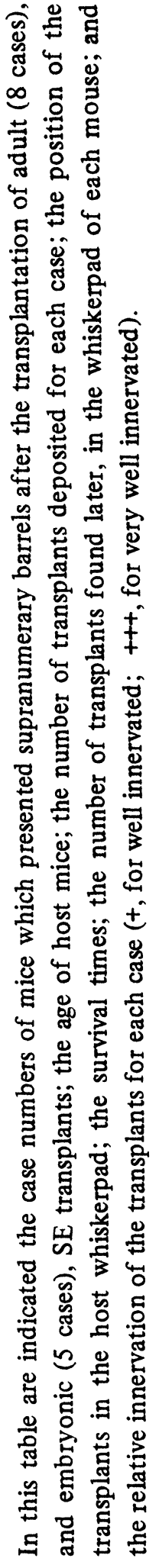


$4 b$
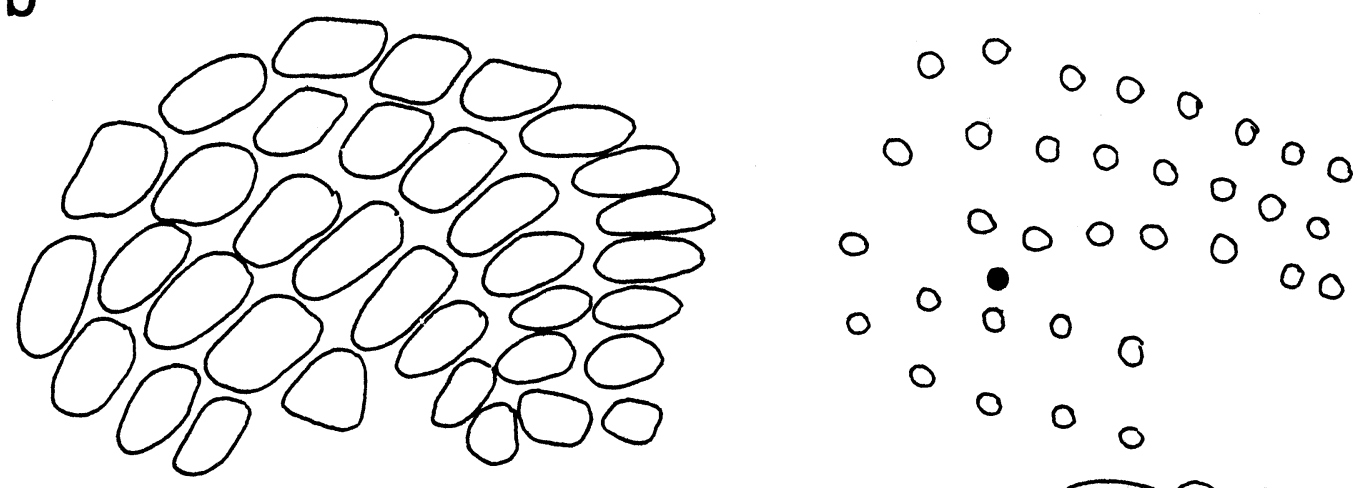

Case 2

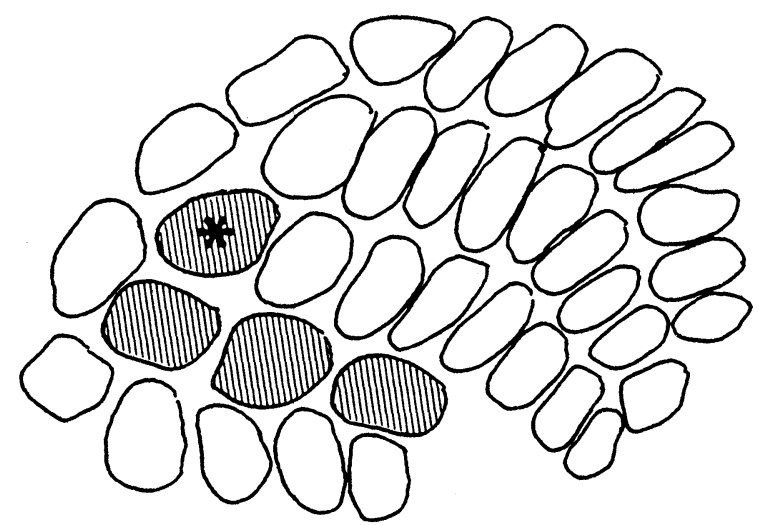

Fig. 4. b) Case 2. Notice the presence of only 3 barrels in row $B$ of the right barrelfield (masked barrels), and the presence of larger barrel $\mathrm{C} 1$ (masked, with asterisc). This corresponds to vibrissal follicle C1, which is close to the implanted SE (see black dot in the drawing of the left whiskerpad in the right upper quadrant).

\section{$4 \mathrm{C}$}

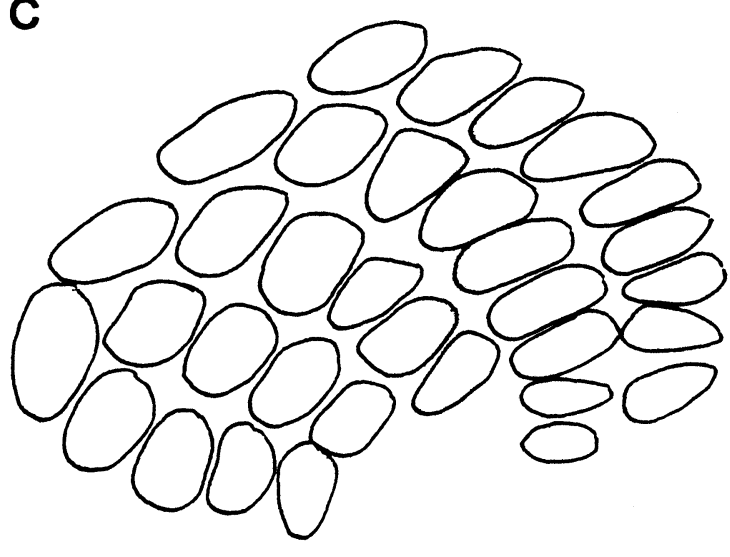

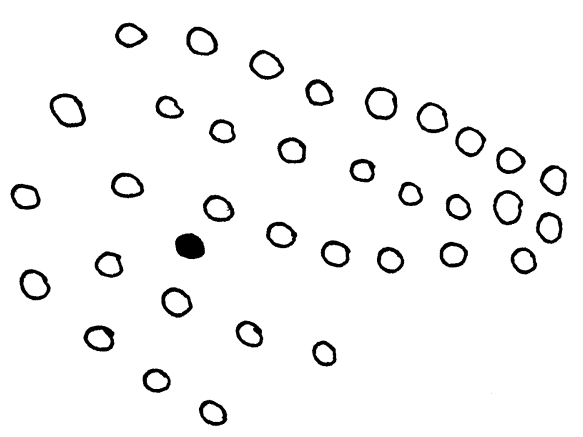

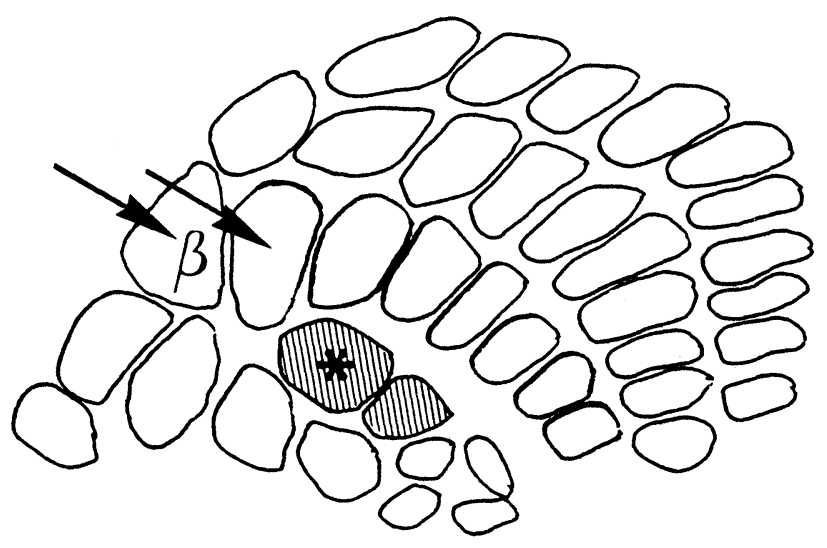

Fig. 4. c) Case 3. Notice the presence of only two barrels in row B (masked), one of which is larger than normal (with asterisc). Arrows indicate larger barrels, straddler $\beta$ and $\mathrm{C} 1$. The black dot in the drawing of the upper right quadrant represents the SE implant deposited between rows B and C. 

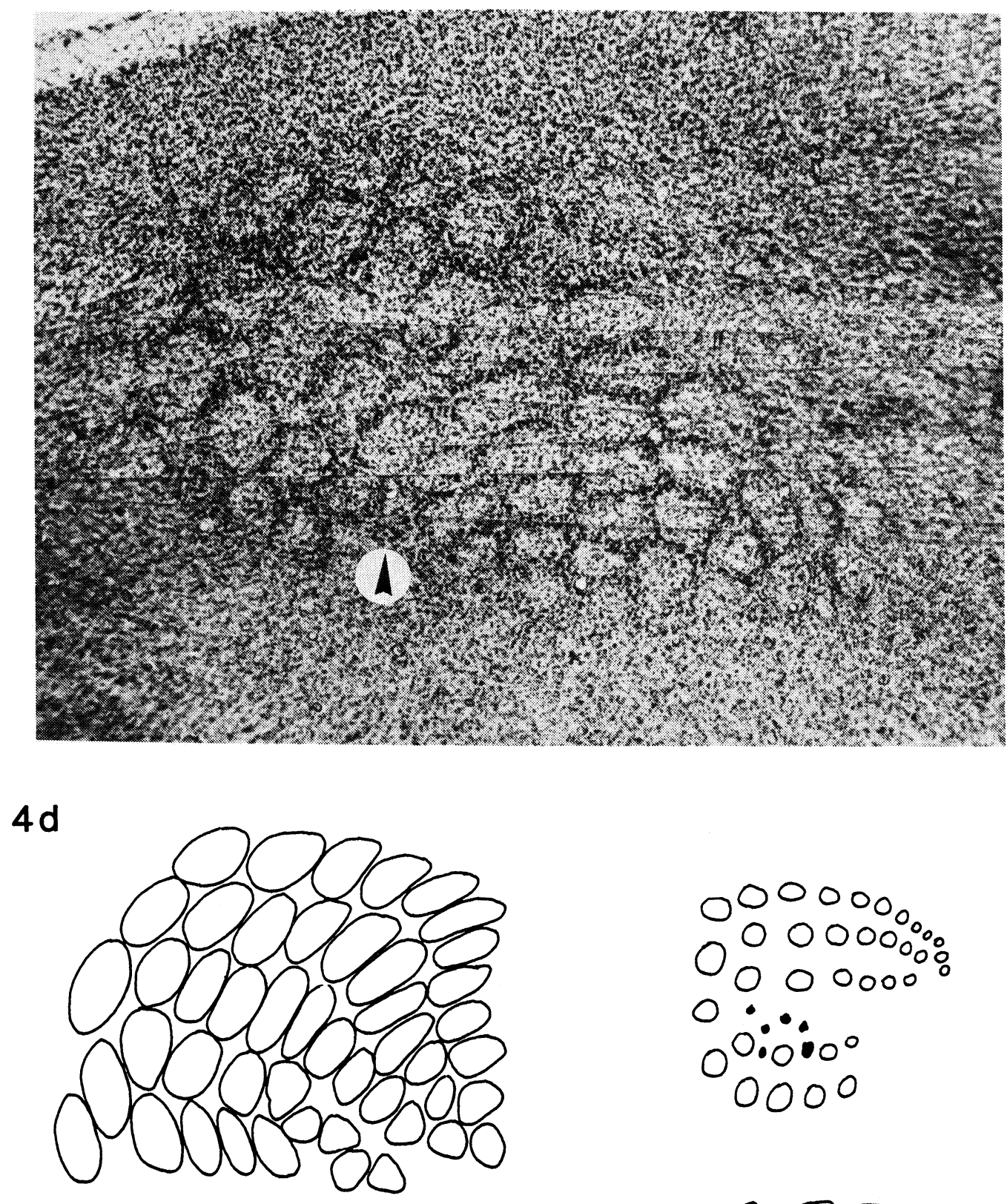

\section{Case 4}

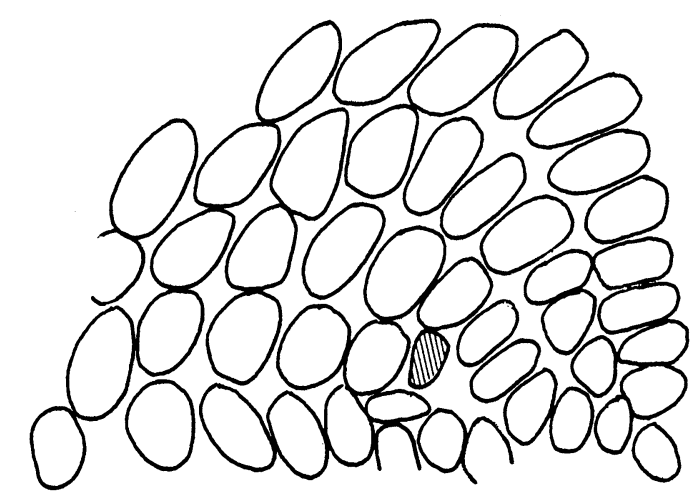

Fig. 4. d) and e) respectively Cases 4 and 5. Notice the presence of a supranumerary barrel (masked) in the rostral part of row B. The same barrel is indicated, for each case, by an arrowhead in the micrograph of the right barrelfield (reconstructed by superposition of serial micrographs of serial sections of the right parietal cortex). Black dots in the drawing of the upper right quadrant indicate final distribution of the $\mathrm{SE}$ implants deposited between rows $\mathrm{B}$ and $\mathrm{C}$. 


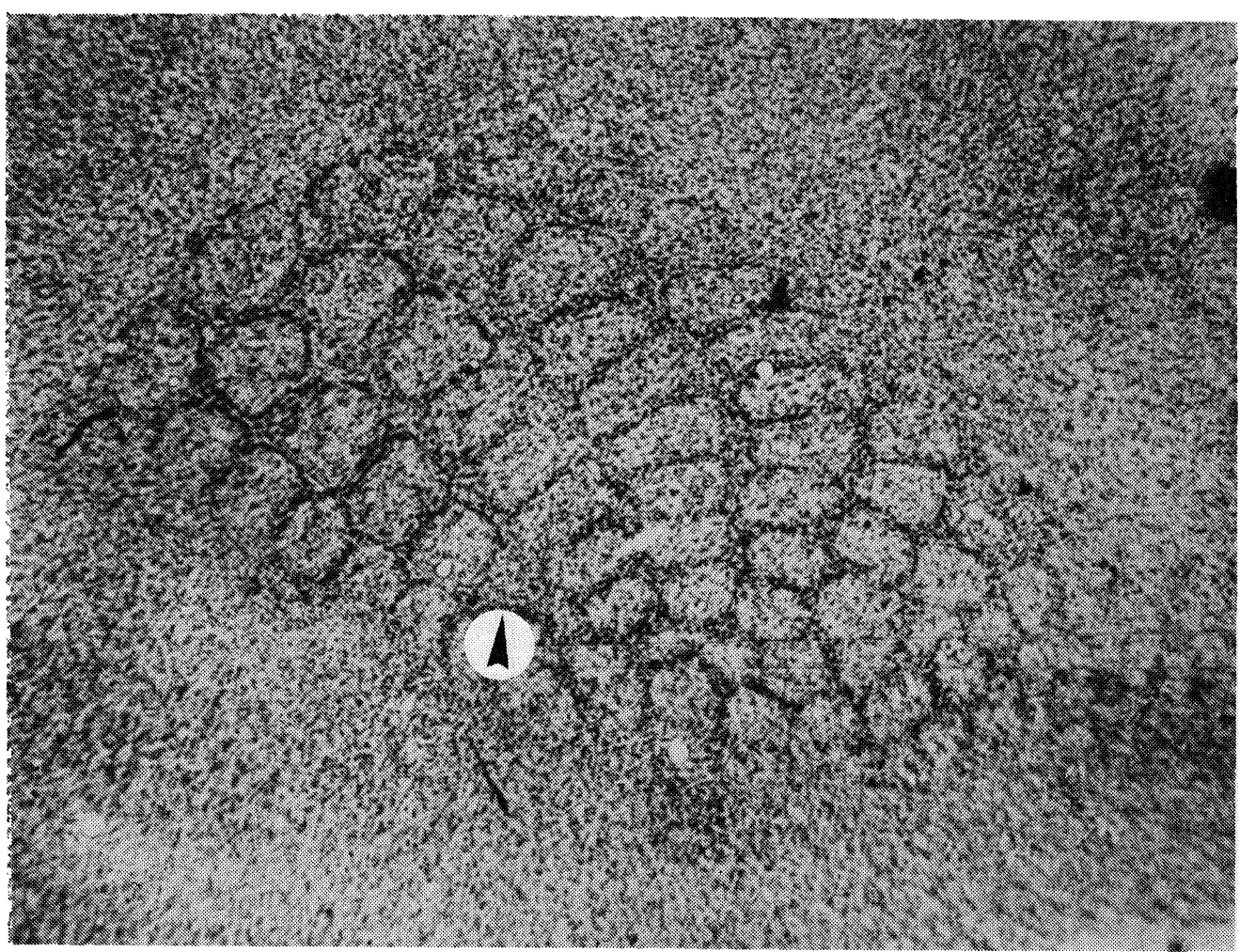

$4 e$
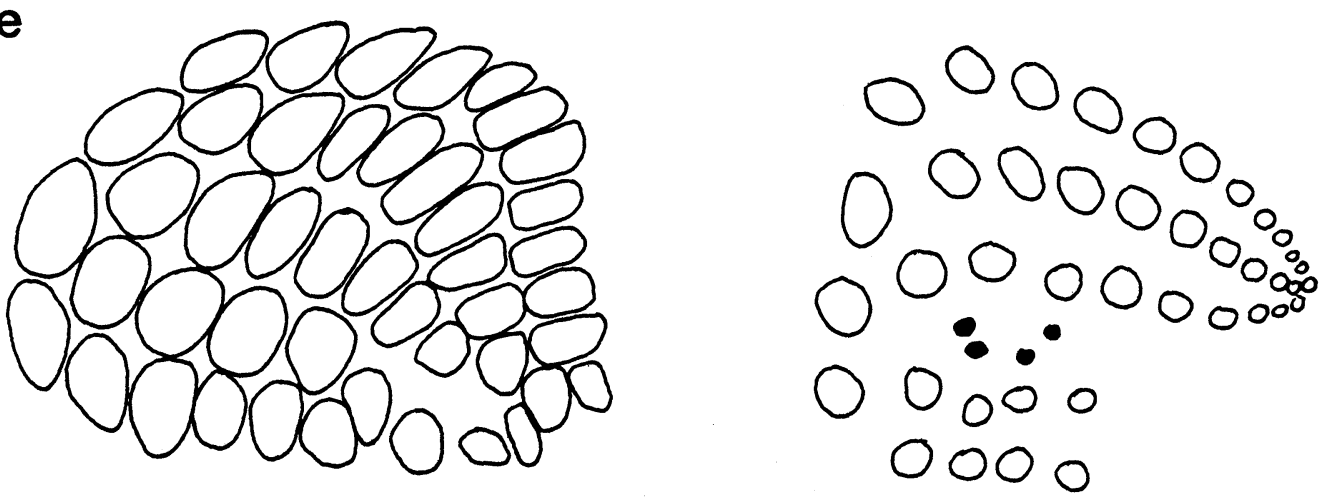

Case 5

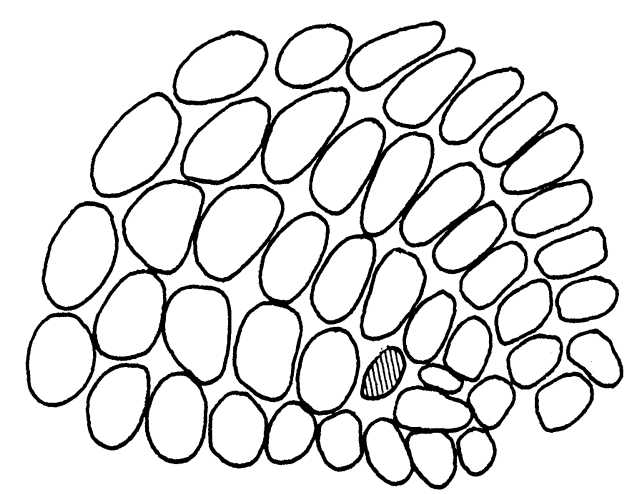

Fig. 4. d) and e) respectively Cases 4 and 5. Notice the presence of a supranumerary barrel (masked) in the rostral part of row B. The same barrel is indicated, for each case, by an arrowhead in the micrograph of the right barrelfield (reconstructed by superposition of serial micrographs of serial sections of the right parietal cortex). Black dots in the drawing of the upper right quadrant indicate final distribution of the $S E$ implants deposited between rows $B$ and $C$. 

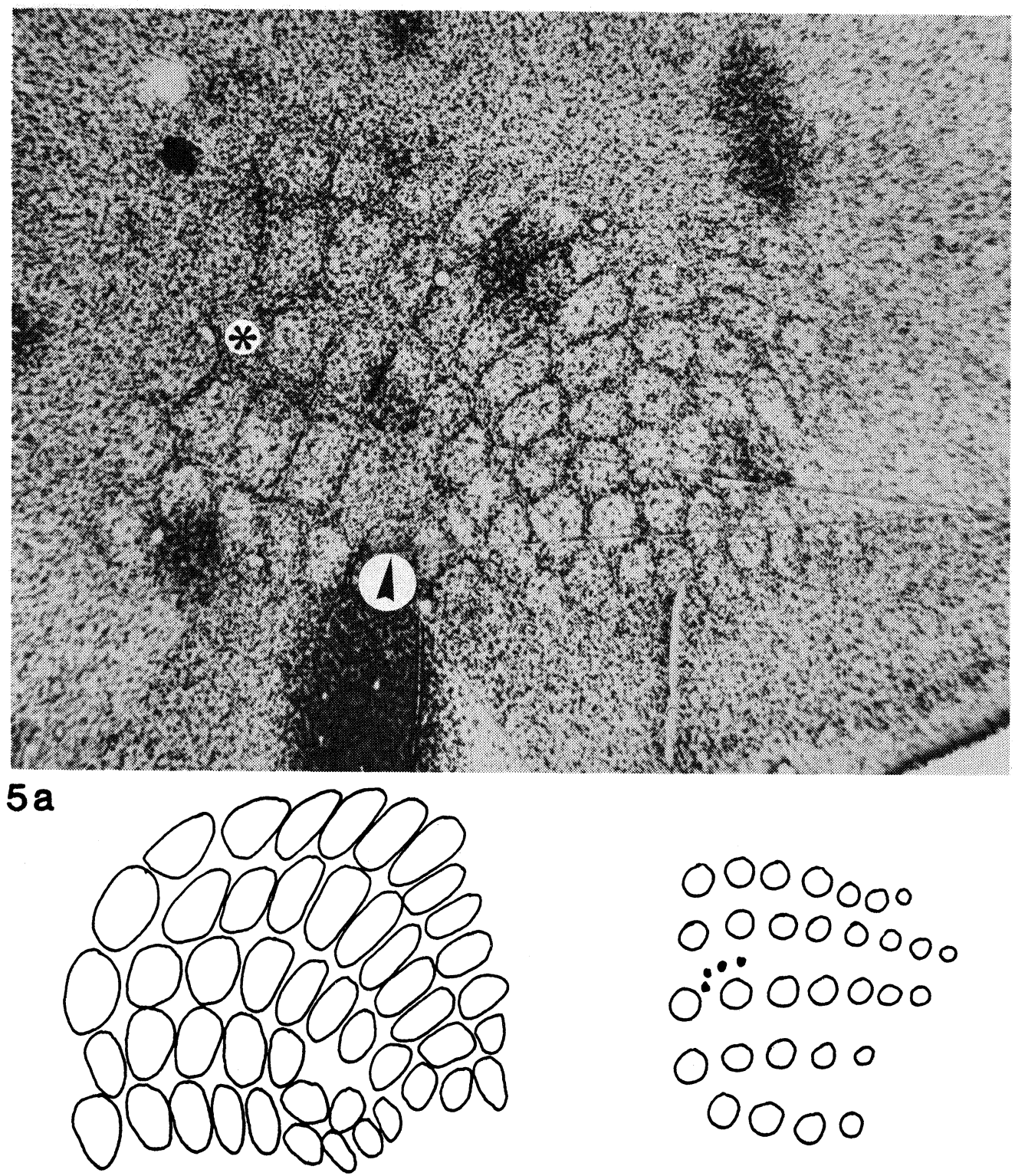

Case 9

Fig. 5. Distribution as in Fig. 4.

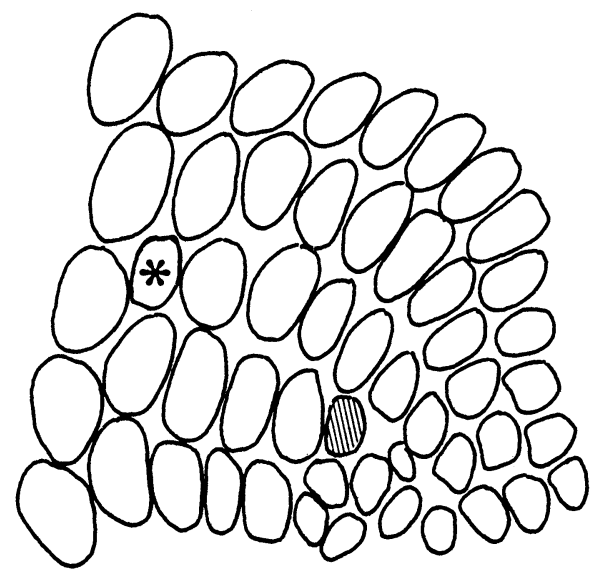

a) Case 9. Supranumerary (masked) barrel in the rostral part of row B. The same barrel is indicated by the arrowhead in the adjacent photomicrograph. $\mathrm{C} 1$ barrel (asterisc) is smaller than the corresponding barrel in the intact, opposite barrelfield. Barrel $C 1$ corresponds to vibrissal follicle $C 1$, which is adjacent to the $S E$ transplants deposited between rows $C$ and $D$ of the left whiskerpad (black dots in the drawing of the right upper quadrant). 
$5 b$

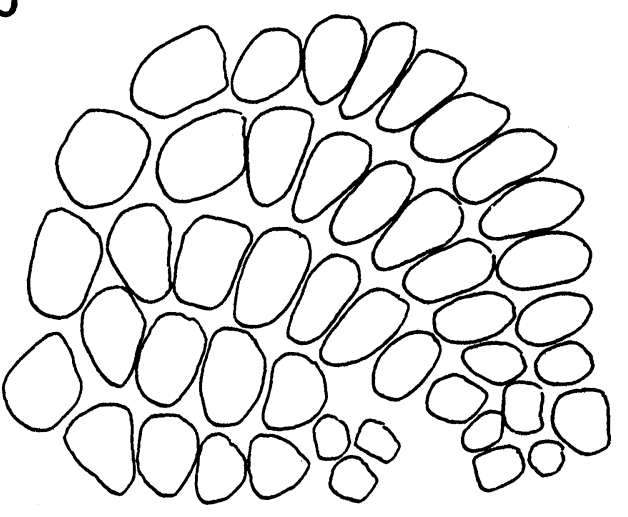

000000000

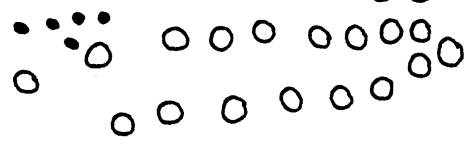

0

$0 \begin{array}{lllll}0 & 0 & 0 & 0 & 0 \\ 0 & 0 & 0 & 0 & 0\end{array}$

Case 10

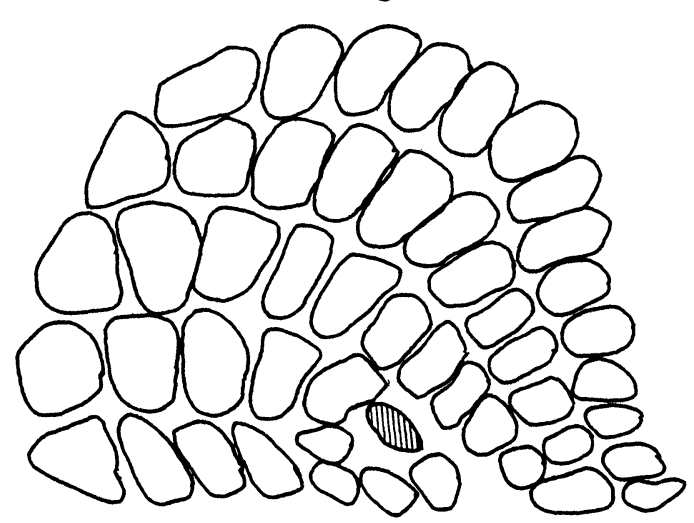

$5 c$
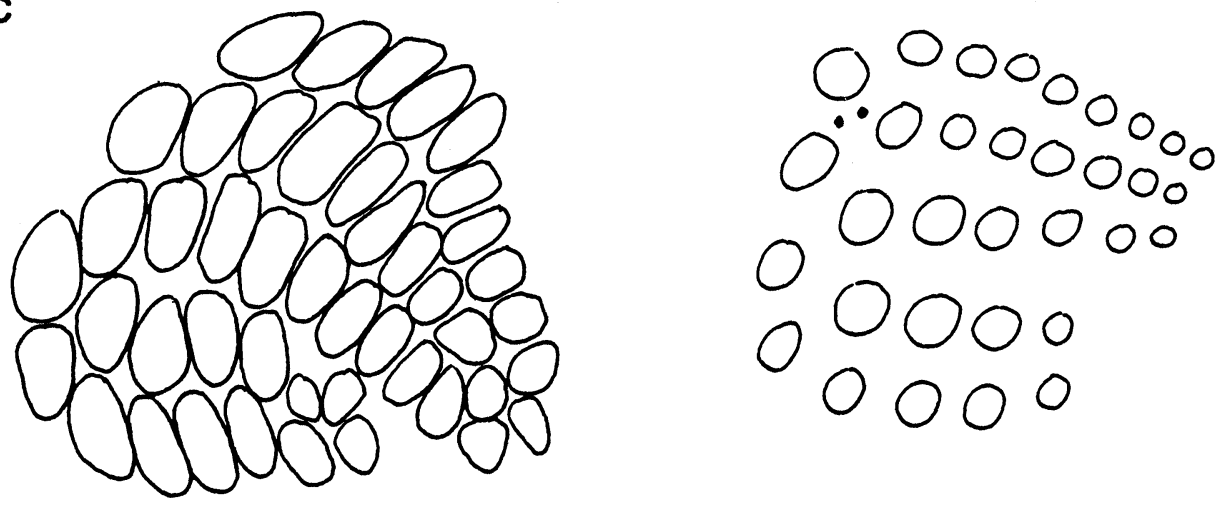

Case 12

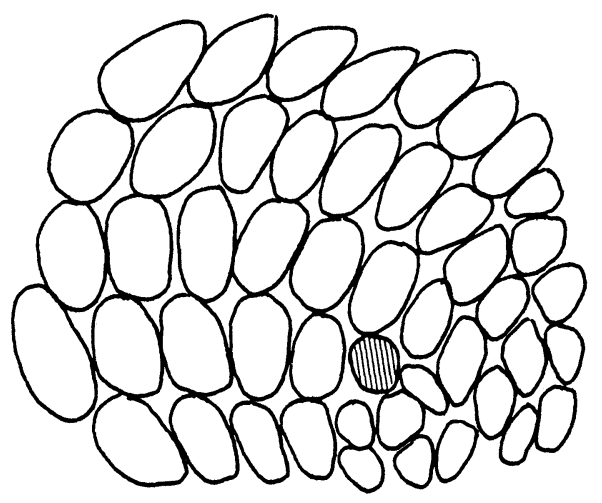

Fig. 5. b), c) and e) respectively Cases 10, 12, and 13. Supranumerary (masked) barrel in the rostral part of row B. Black dots indicate final distribution of $S E$ implants deposited between rows $C$ and $D$ of the left whiskerpad. 
$5 d$

\section{Case 11}

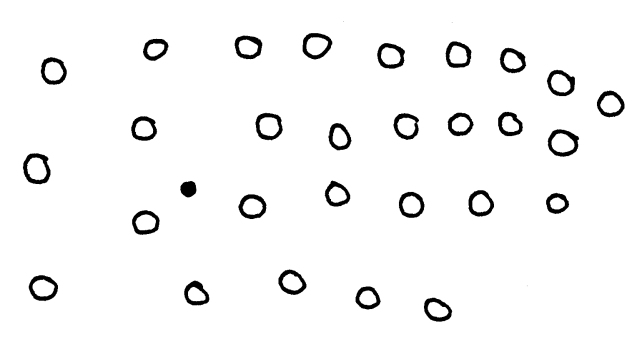

00000

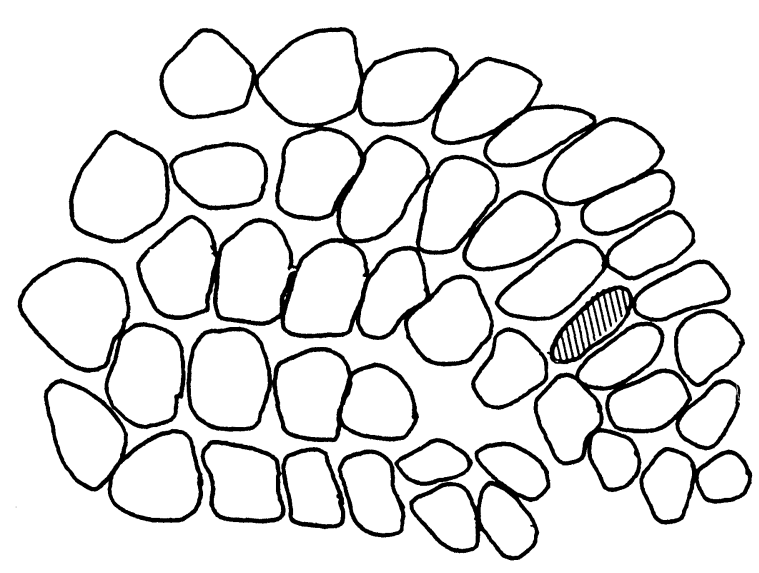

$5 e$

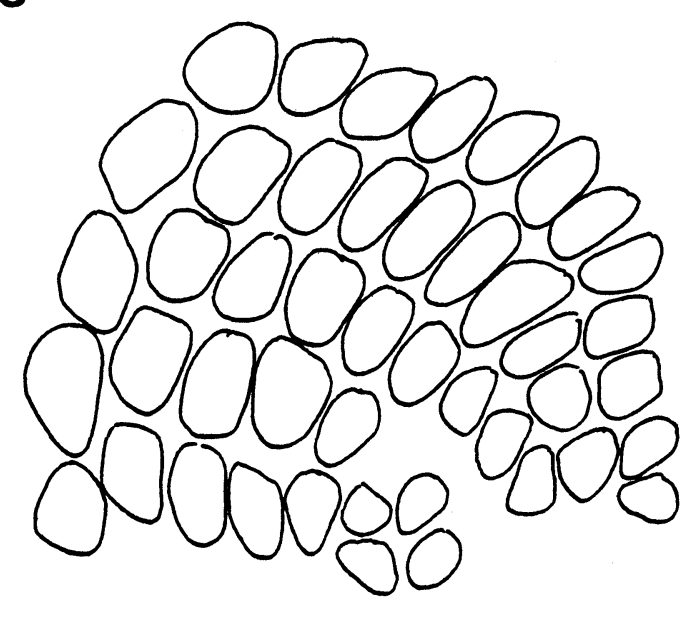

00000000

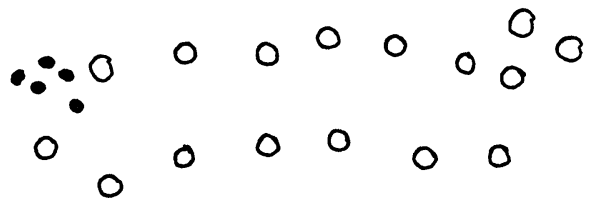

0
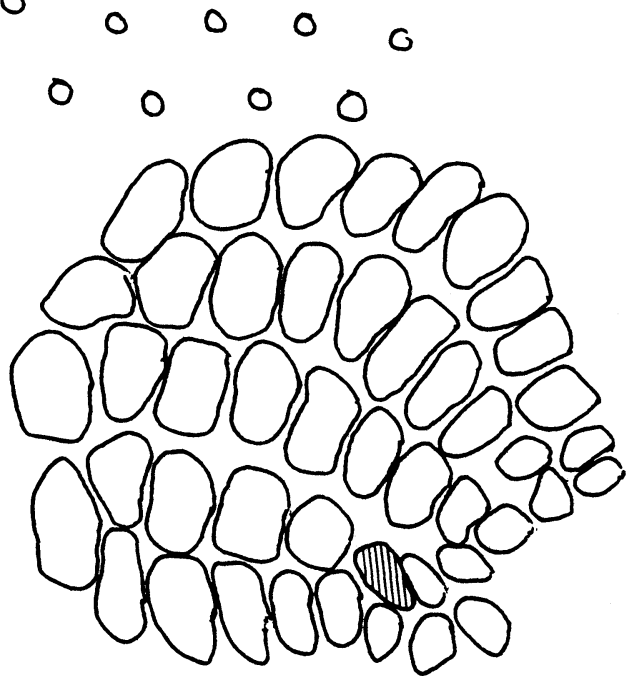

Fig. 5. d) Case 11. Supranumerary (masked) barrel in the rostral part of row D. Black dot indicates the final position of the only SE implant found in this case. 


\section{DISCUSSION}

The results of these experiments show that the transplantation of a large number of receptors (contained in the SEs of vibrissal follicles), to the whiskerpads of newborn mice induced the formation of "new", supranumerary barrels in the corresponding somatosensory cortex of 10 , out of the 24 mice that received the transplants.

In order to induce the formation of "new" barrels the SEs had to be well innervated by the host nerve fibers, as shown in the Results. Their innervation could have two different origins. One from the facial nerve, and the other from the trigeminal nerve $/ 5 /$. Most probably, the SEs of the 3 cases of the first group of operated mice, which were well innervated but not represented in the barrelfield, have received their innervation from the facial nerve. It has been demonstrated that this nerve although important for the mobility of the vibrissal follicles, does not participate in the production of the barrelfield /8/. However, in the cases in which supranumerary barrels were found, one must admit that the innervation of the SEs was most certainly and predominantly made by the trigeminal nerve. This is the responsible nerve for the sensory innervation of the vibrissal follicles, the first link in the whiskerpad-to-barrelfield system.

The non-existence of a topological representation of the supranumerary barrels suggests that there was a priority for the imprinting in the somatosensory cortex of the barrels corresponding to normal vibrissal follicles. The imprinting of the "new" barrels appears to be secondary, and made in territories of the somatosensory cortex, receiving relatively less important projections from the periphery. In this context it is interesting to acknowledge that the supranumerary barrels were always found in regions of the somatosensory cortex where banal skin of the whiskerpad is usually represented (for instance, the rostral part of row B; see the coarse-stippled area in Fig. 4, of the electrophysiological study made by Nussbaumer and Van der Loos /7/). This was the situation found in cases $4,5,6,7,8,9,10,11,12$, and 13 .

The innervation of the transplants deposted in case 1 , by collaterals of the nerve fibers normally innervating one adjacent vibrissal follicle, may explain the existence of a larger than normal barrel in this case.

On the contrary, the absence of normal barrels together with the presence of adjacent enlarged barrels suggests that, in these cases, the nerve fibers innervating the vibrissal follicles corresponding to the missing barrels were interrupted $/ 6 /$.

In conclusion, the supranumerary barrels representing the SEs deposited in regions of banal skin of the whiskerpad were formed in the regions of the somatosensory cortex, in which banal skin is usually represented.

\section{ACKNOWLEDGEMENTS}

I thank M.C. Cruz for help with histology; S. Daldoss for photography. This study was supported by the Swiss National Science Foundation, grant no. 3158.

\section{REFERENCES}

1. Andres, F.L. Early substitution of whiskerpad by dorsal skin, cornea and palm of forepaw thoroughly modifies structure of barrelfield in mice. Anat. Embryol. 173: $157-161$ (1985).

2. Andres, K.H. Uber die Feinstruktur der Rezeptoren an Sinus-haaren. Z. Zellforsch. 75: 339-365 (1966).

3. Andrés, F.L. and Van der Loos, H. From sensory periphery to cortex: the architecture of the barrelfield as modified by various early manipulations of the mouse whiskerpad. Anat. Embryol. 172: 11-20 (1985).

4. Cruz, M.C., Jeanmonod, D., Meyer, K. and Van der Loos, H. Silver and gold technique for axons and axon-bundles in formalin-fixed central and peripheral nervous tissue. J. Neurosci. Meth. 10: 1-8 (1984).

5. Dorfl, J. The innervation of the mystacial region of the white mouse. A topographical study. J. Anat. 142: 173184 (1985)

6. Jeanmonod, D., Rice, F.L. and Van der Loos, H. Mouse somatosensory cortex: alterations in the barrelfield following receptor injury at different early postnatal ages. Neuroscience 6: 1503-1535 (1981).

7. Nussbaumer, J.-C. and Van der Loos, H. An electrophysiological study of projections to the mouse cortical barrelfield and its surroundings. J. Neurophysiol. 53: 686-698 (1985).

8. Rice, F.L. Neonatal facial nerve extirpations fail to produce alterations in the barrel field in the primary somatosensory cortex of mice. Brain Res. 322: 393-395 (1984).

9. Van der Loos, $H$. The development of topological equivalences in the brain. In: Meisami E. and Brazier M.A.B. (Eds.), Neural Growth and Differentiation. Raven Press, New York, pp. 331-336 (1979).

10. Van der Loos, H. and Dorfl J. Does the skin tell the somatosensory cortex how to construct a map of the periphery? Neurosci. Lett. 7: 23-30 (1978). 

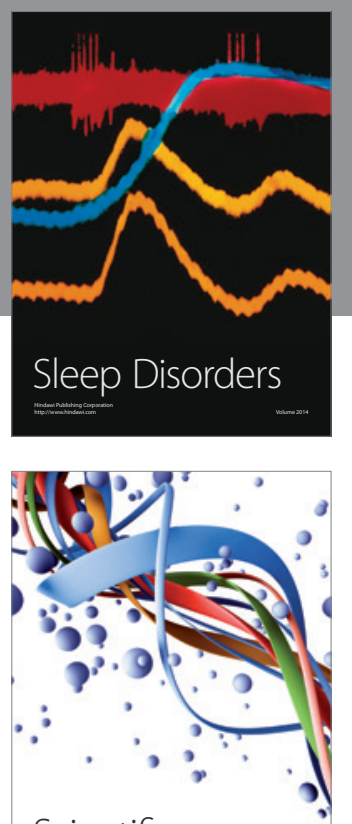

Scientifica
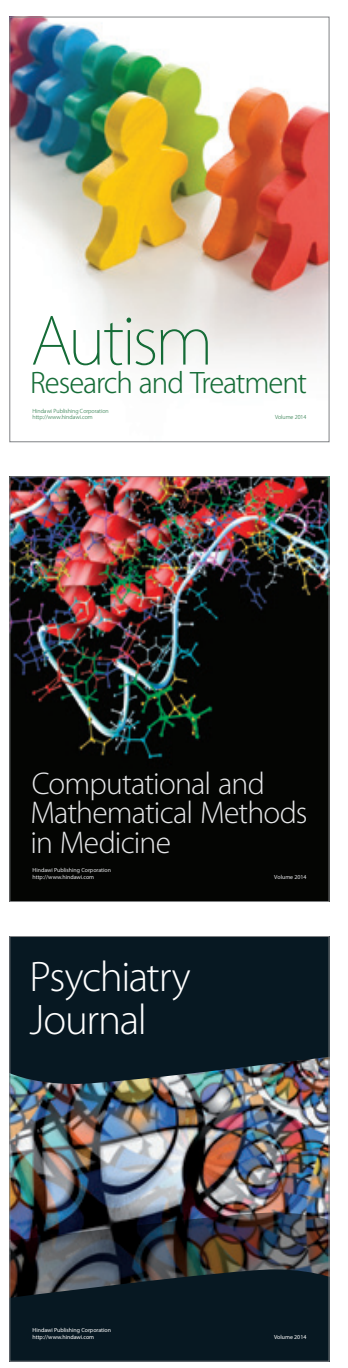
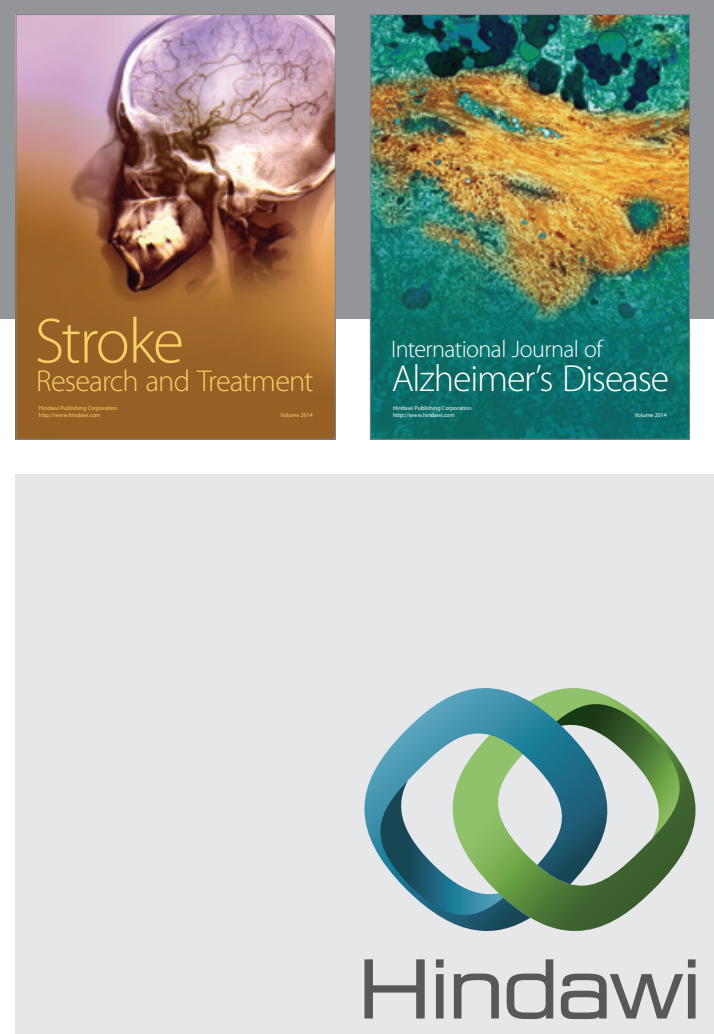

Submit your manuscripts at

http://www.hindawi.com
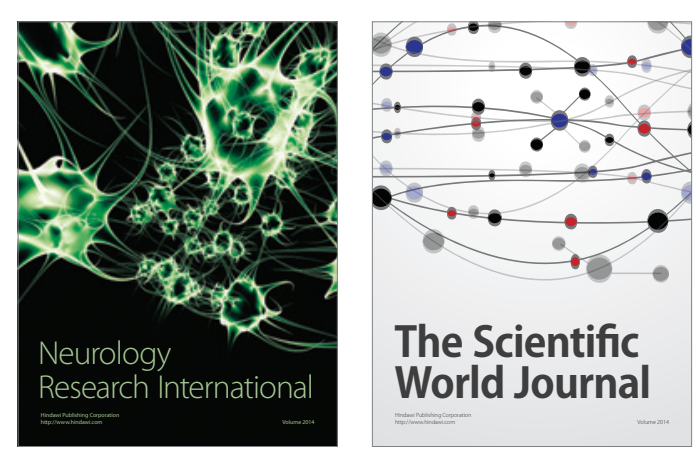

The Scientific World Journal

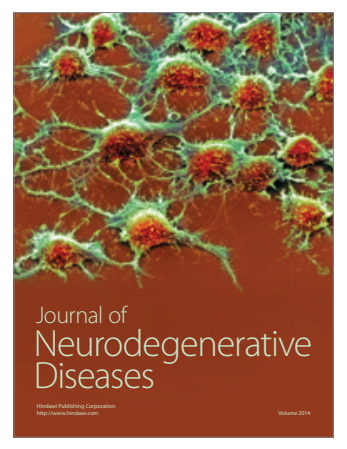

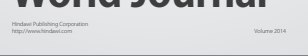

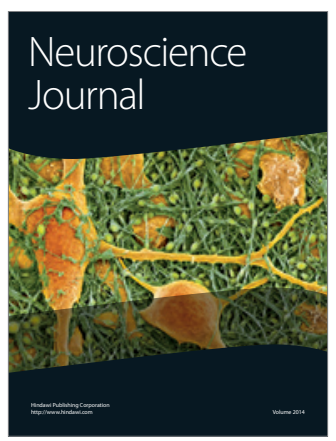

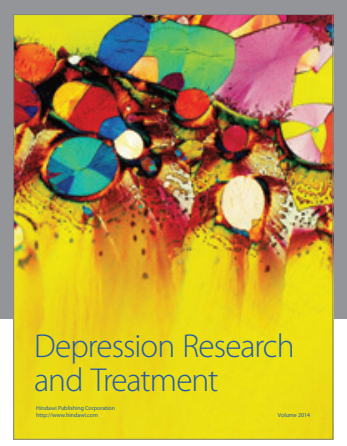
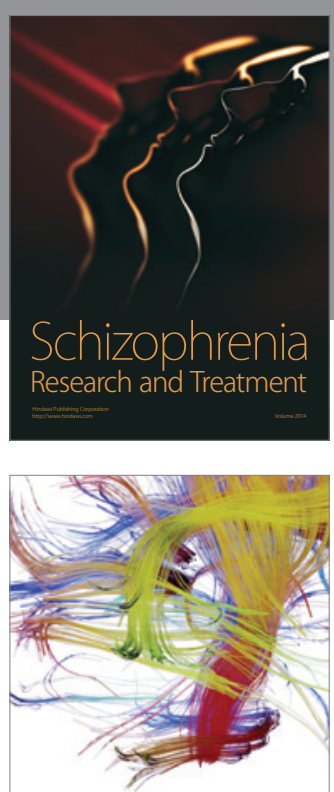

Brain Science

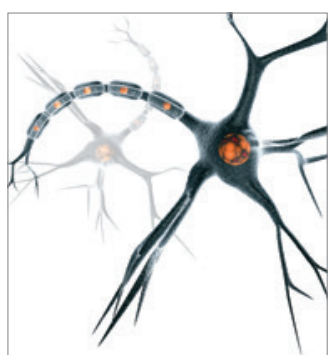

Neural Plasticity
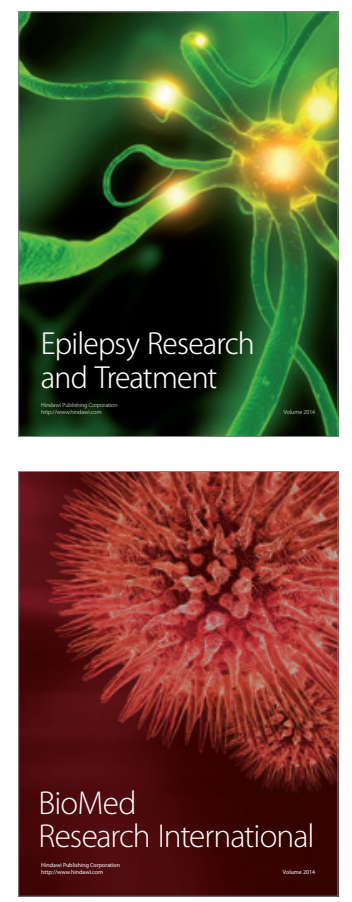

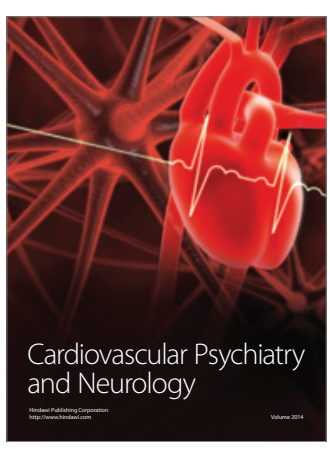

Parkinson's

Disease
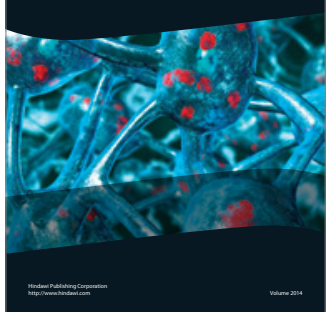